\title{
SOCIO-PSYCHOLOGICAL ADAPTATION OF THE FIRST-YEAR STUDENTS OF THE ECONOMIC UNIVERSITY AS A COMPONENT OF INDIVIDUAL PROFESSIONAL DEVELOPMENT IN THE CONTEXT OF CULTURAL AND EDUCATIONAL SPACE
}

\author{
Volodymyr Morozov \\ Prof. DSc, Kryvyi Rih Economic Institute of Kyiv National Economics University named \\ after Vadym Hetman, \\ e-mail: morozov_vv@kneu.dp.ua, orcid.org/0000-0002- 9228-8974, Ukraine \\ Liliya Mykhailenko \\ Associate Prof. PhD, Kryvyi Rih Economic Institute of Kyiv National Economics University \\ named after Vadym Hetman, \\ e-mail: liliyamix914@gmail.com, orcid.org/0000-0003-4353-4769, Ukraine \\ Natalia Falko \\ Associate Prof. PhD, Melitopol State Pedagogical University named after Bohdan \\ Khmelnitsky, \\ e-mail: falkontaliya@gmail.com,orcid.org/0000-0001-9475-6770, Ukraine

\section{Edward Rojasdela Puente} \\ $\mathrm{PhD}$, Universidad nacional toribio rodriguez de mendoza Amazonas, \\ e-mail: edenrop@hotmail.com, orcid.org/ 0000-0001-9026-1244,Peru \\ Andrii Galaidin \\ MA, Polonia University in Czestochowa, \\ e-mail: a.galaidin@ap.edu.pl, orcid.org/0000-0002-5236-1495, Poland
}

\begin{abstract}
The article gives a theoretical analysis of existing in modern science approaches to the study of the problem of students' adaptation to study in higher educational institutions. A comparative description of the components of the adaptation process is presented. The necessity of provision psychological support for the process of students' adaptation to higher education studies is determined. A training program is proposed for improving the level of adaptability of freshmen students and maladaptation prevention in terms of studying at an economic higher education institution.
\end{abstract}

Keywords: adaptation, adaptive potential, cultural-educational space, personality, students-freshmen.

DOI: http://dx.doi.org/10.23856/2411

\section{The problem topicality}

In the conditions of reforming the higher education of Ukraine and its integration into the European scientific, cultural and educational space, issues of high-quality vocational training of specialists, competitive in the labor market, are of great importance. The system of higher education varies very quickly: new methods, methodology and approaches to learning are emerging, new branches are being developed, new specialties are opened up, the prestige of certain professions increases, and others are decreasing, the tendencies of higher education change. But the problem of socio-psychological adaptation of students to study at higher educational institutions remains the same. After all, yesterday's schoolchildren, coming to the 
university, also feel uncertainty about future actions, excitement over new experiences, etc., which are part of the process of adaptation. And this process continues with the acquisition of a new social status, getting used to the new conditions and the rhythm of life and education, development of new skills and abilities, acquisition of new experience, formation of new personal qualities as an individual and as a member of a new society (students, teachers, neighbors in the hostel) and so on.

Representatives of psychology, sociology, philosophy, biology, physiology, pedagogy paid lot of attention to the problem of adapting students to the studies at universities. But topicality and the need to study this problem did not become less due to this. There are certain contradictions in many aspects of studying the problem of socio-psychological adaptation of students to the studies at universities, start with the definition of this concept, selection of stages, factors, mechanisms of this process, continuing with developing effective strategies, methods, tools and techniques for successful adaptation.

The purpose of the paper is to analyze existing approaches in modern science to the problem of adaptation of students to the studies at higher educational institutions, in particular, socio-psychological adaptation of students to the studies at an economic higher education institution in Ukraine.

\section{Results of the research problem analysis}

The problem of the person adaptation has found a fairly wide reflection in the works of scientists. General notions about adaptation, its regularities and physiological mechanisms were studied by M.O. Agadzhanyan, A.A. Nalchadzhyan, O.O. Rean, A.I. Clinciu, R. Dyson, C.L. Park, James D.A. Parker (Agadzhanyan, 2009; Nalchadzhyan, 2010; Rean, 2006; Clinciu, 2013; Dyson, 2006; Park; 2012; Parker James, 2004). Among the domestic studies of adaptation of students and young specialists and the problem of adaptation as a form of social activity of the individual we should, first of all, indicate the work of T.V. Alekseeva, O.M. Galus, V.D. Ostrova, V.A Semichenko, S.V. Kharchenko and others (Alekseeva, 2004; Galus, 2012; Ostrova, 2015; Semichenko, 2003; Kharchenko, 2010). General problems of socio-psychological adaptation and the formation and development of adaptive personality characteristics were reflected in the scientific works by B.G. Ananyev, F.B. Berezin, A.V. Furman (Ananyev, 2002; Berezin, 1988; Furman, 2000). The role of mechanisms of psycho-physiological regulation in providing adaptive processes was studied by R.M. Bayevskyi, O.M. Kokun, F.Z. Meerson (Bayevskyi, 2004; Kokun, 2004; Meerson, 1988).

One of the important directions of adaptation exploration is the consideration of social adaptation as a process and the result of an active adaptation of an individual to the conditions of a new social environment. Social adaptation is considered not only as a adjustment, but as a permanent process of integration of an individual into society, the process of his/her active adaptation in the social environment. Thus, the notion of social adaptation comes close to the notion of "socialization" - the process of assimilating an individual's social experience, a certain system of knowledge, norms, values that allow him/her to function as a full member of society (Con, 1979). The difference in the psychological definitions of adaptation - in the emphasis on the activity of the process. They emphasize the activity of the subject, and not only the one-sided influence of the environment.

Rean O.A. approaches to the definition of adaptation from other positions, focusing not on changing the behavior of a subject in accordance with the conditions of the social 
environment, but on the procedural aspect: adaptation is "the process and result of internal changes, external active adaptation to new conditions of existence and self-change of an individual " (Rean, 2006, p.10). At the same time, he highlights two patterns: firstly, adaptation to changed conditions take place (changes in the structure of social values, organizational transformations, improvements and innovations in technology); secondly, and this aspect directly overlaps with our problem, this is adaptation - entering into a new professional activity.

At the same time A.A. Nalchadzhyan emphasizes that "The essence of social and psychological adaptation is the successful assimilation to the new conditions of activity and entering, "fitting into" a system of new official and - more importantly - informal relationships, finding and occupation in a new micro-environment of a certain status, selfaffirmation in an emotionally comfortable, prospectively encouraging position "(Nalchadzhyan, 2010, p.24). The author gives the following classification of sociopsychological adaptability of personality: 1) temporary situational adaptation, which can easily become a state of maladaptation as a result of intra-psychological changes (for example, updating of new needs and settings), or changes in some aspects of the situation; 2) stable situational adaptation - long-term adaptability in certain typical situations, in which the individual appears to be quite often; 3) general adaptability - the potential ability to adapt in a wide range of typical situations that are most commonly encountered in this social environment (Nalchadzhyan, 2010, p. 67).

An important aspect of the problem is selection of adaptation criteria. Since adaptation is based on the interaction of two parties, it is natural that the criteria of adaptability maladaptation also need to evaluate the process in two ways: both from the environment part and from the individual's part: not only the survival of persons and finding their place in the social structure, but also the overall level of psychological health, ability to develop in accordance with their life potential, a subjective sense of self-esteem and awareness of life (Ostrova, 2015).

As a rule, most researchers distinguish between two main adaptation criteria: external and internal (Alekseeva, 2004; Berezin, 1988; Glivinska, 2015). The external criterion is closely related to the notion of "adjustment". The result of adaptation is understood as the attainment of the desired behavior in the environment and is described in terms of efficiency, competence, and success. The external criterion usually determines good adaptability, compliance with environmental requirements.

Thus, the process of adaptation can be mainly directed to adapt to the requirements of the environment, or to seek opportunities for the realization of subjective aspirations and to meet the needs of the individual. Then they say that the adaptation is oriented to the external or internal criterion. Accordingly, the resulting state of adaptability can also be considered from the point of view of compliance with the environmental requirements (external criterion), or the needs of the individual (internal criterion).

The difficulties of reconciling the external and the internal reflect the problem of the relationship between the individual and the environment, and is the main task and goal of the process of adaptation. Therefore, if the main problem of the adaptation process is in the coordination of the internal and the external, then only optimal adaptation can be considered as a result that meets the requirements of two criteria (Glivinska, 2015).

Indicators of adaptation of an individual by external criterion are achievements in different types of activities and communication, and evaluation of these indicators is carried out both by the subject (attitude to own results, depending on the level of claims), and by the 
social environment (the level of conformity of activity and behavior subject to social standards). As an important indicator of adaptation of the person according to the internal criterion are self-adaptation, self-actualization and motivational conditionality of the selfconcept of personality.

The philosophical concept of adaptation is presented as a description of the general principles of dialectical unity of the organism (individual, their total) and the environment: alterations and permanency, dynamics and stability, passivity and activity, openness and closeness (Rean, 2006).

Thus, it becomes obvious that the very definition of the term "adaptation" has a complicated philosophical and methodological problem. As A. B. Heorhievskyi showed on the basis of a comparative analysis of a large number of definitions of adaptation, all the definitions of the concept of adaptation can be grouped into the following groups:

- tautological definitions in which the concept of adaptation is interpreted as the literal translation of the Latin "adapto" (adaptation) in the sense of the adaptation of organisms to the environment, that is, "adaptation" is the process and result of adaptation of the structure and functions of the organism (individuals, populations, species) and their organs to the environment;

- definition through the "main sign". Here, adaptation is interpreted through the severity of the key aspect of the structural and functional organization of the individual. These key aspects are distinguished at the following levels: biochemical, morphological, physiological, behavioral. For example, "physiological adaptation should be understood as a set of physiological features that determine the balance of the organism with constant or variable environmental conditions" (Georgiyevsky, 1989, p.34).

- a polysemantic definition, which emphasizes the multi-valued and multi-faceted nature of the phenomenon of adaptation, and, above all, differentiation of adaptation as a process and adaptation as a result.

The most complicated and heterogeneous aspects of the phenomenon of adaptation are manifested in the multifaceted human activity, in which psycho-physiological, behavioral, cognitive and subjective-personal components of the adaptation process can be distinguished.

Analyzing the concepts of adaptation proposed by various sciences, one can argue that it is regarded as a phenomenon, state, process, property, result and dynamic formation.

Adaptation as a physiological phenomenon is a process of adaptation to environmental conditions, during which the ability of individuals and their groups to survive improves. Adaptation as a state is a degree of satisfaction of the individual's needs under the conditions of the environment. Adaptation as a process is a form of change in the environment and the organism by applying actions, corresponding situations, to achieve a simultaneous equilibrium between the environment and the organism. Adaptation as a property (adaptability) is a characteristic of a self-regulated system that ensures its resistance to environmental conditions and variability under the influence of these conditions, which involves the development of certain adaptive abilities. Adaptation as a dynamic entity is a process of adaptation to the environment, but active, driven by the emotional-volitional sphere. Adaptation as a result is adaptedness, that is, the availability of adjustment to a certain factor of the environment.

In order to study the peculiarities of the socio-psychological adaptation of the students of the first year of the law department of Kryviy Rih Economic Institute of KNEU named after Vadym Hetman, we used the methodology of K. Rogers, R. Diamond "Diagnosis of 
social and psychological adaptation" (Fetiskin N.P. et al., 2002). The testers evaluated the proposed statements about a person, about his/her way of life, experiences, thoughts, habits, behavioral styles on a seven-point scale.

For statistical analysis of the results of the psycho-diagnostics of the results distribution in the groups, the non-parametric U-criterion by Mann-Whitney was used. From the data given in Table. 1, one can conclude that there are no statistically significant differences between the experimental group (PR-17-2) and the control group (PR-17-1, PR-17-3) of freshmen students according to the criteria of the method of research of social-psychological adaptation of statistically significant differences.

Table 1

\section{Indicators of socio-psychological adaptation of first-year students of economic universities at the stage of establishing experiment}

\begin{tabular}{|c|c|c|c|c|c|c|c|}
\hline \multirow{3}{*}{ No. } & \multirow{3}{*}{ Non-constant } & \multicolumn{6}{|c|}{ Investigated groups } \\
\hline & & \multicolumn{2}{|c|}{$\begin{array}{l}\text { Experimental } \\
\quad \mathrm{N}=20\end{array}$} & \multicolumn{2}{|c|}{$\begin{array}{c}\text { Control } \\
\mathrm{N}=36\end{array}$} & \multirow{2}{*}{$\begin{array}{c}\text { Significance } \\
\text { level }\end{array}$} & \multirow{2}{*}{$\begin{array}{l}\text { Empiric } \\
\text { value of } \\
\text { the } \\
\text { criterion }\end{array}$} \\
\hline & & $\begin{array}{l}\text { Average } \\
\text { value }\end{array}$ & $\begin{array}{l}\text { Std. } \\
\text { dev. }\end{array}$ & $\begin{array}{l}\text { Average } \\
\text { value }\end{array}$ & $\begin{array}{l}\text { Std. } \\
\text { dev. }\end{array}$ & & \\
\hline 1 & Adaptation & 53.38 & 4.16 & 53.67 & 5.41 & 0.5299 & 176 \\
\hline 2 & Emotional comfort & 51.16 & 7.46 & 50.47 & 9.82 & 0.9148 & 195.5 \\
\hline 3 & $\begin{array}{l}\text { Striving to } \\
\text { dominate }\end{array}$ & 41.01 & 12.32 & 38.79 & 18.26 & 0.7282 & 186.5 \\
\hline 4 & Internality & 54.89 & 3.94 & 56.75 & 6.42 & 0.1276 & 142.5 \\
\hline 5 & $\begin{array}{l}\text { Perception of the } \\
\text { others }\end{array}$ & 55.17 & 13.23 & 60.48 & 9.36 & 0.2396 & 155.5 \\
\hline 6 & Self-perception & 57.98 & 9.83 & 54.36 & 8.86 & 0.4787 & 173 \\
\hline
\end{tabular}

Note: * Level of statistical reliability at $\mathrm{p} \leq 001$

Consequently, we can say that certain groups are similar to the studied indicators and, accordingly, we can check the effectiveness of the training program to increase adaptive capacity in these groups. According to the results of this study, it can be assumed that the use of training technology in the group of freshmen students causes certain changes in the level and criteria of adaptation to the new conditions of study at an economic higher education institution.

One of the means of increasing the level of adaptability and prevention of maladaptation in freshmen students under the conditions of economic universities can be training lessons that, upon their effectiveness, require less time costs than individual work with students.

The program consists of a system of consistently constructed but relatively independent classes integrated into a comprehensive training system, based on theoretical and methodological provisions on the development and implementation of psychological training.

Over the last decade, a number of theoretical approaches and practical directions of the organization of psychological support of the individual in self-development and selfdetermination have been developed, and the main characteristics of a person as a subject of his own life are marked (Vachkov, 2001; Westbrook, 2014; Kiselev, 2007).

We adhere to the cognitive-behavioral model of psychological training, which has been actively developing recently (Westbrook, 2014). In this model, people behavior is considered 
inextricably linked with their self-perception and the interpretation of their actions. People does not just commit acts, they somehow explains their reasons. Self-perception of a person, his/her idea of how he/she perceives the environment, as well as awareness of his/her own experience, desires and needs, largely determine his/her behavior. Quite often, in the interpretation of own behavior, one can observe the protective mechanisms of the psyche, which are not realized by the persons themselves, but are aimed at preserving the integrity of the individual. Therefore, in order to change the non-constructive behavior, it is also necessary to influence the cognitive constructs that are identified by the participants during the identification process and as a result of feedback.

The laws of mental development of adolescence, living conditions (residing in a rented apartment or at home), personal and psycho-physiological features of students that were found during the survey were also accepted as the basis of our program.

The program is aimed at forming social and communicative competences that contribute to increasing the level of adaptation of freshmen students, the development of cognitive processes, goal-setting, the encouraging the possibilities of establishing contact in various communication situations, expanding the range of creative abilities, self-regulation skills, constructive overcoming of difficulties (intrapersonal and interpersonal conflicts), stress-resistance training.

On the basis of the components of socio-psychological and psychophysical adaptation, as well as the analysis of psychological and pedagogical literature devoted to the means and methods of psycho-correction work, all the methods chosen by us in the program of adaptation training are aimed at: activating in students cognitive, emotional, reflexive, motivational and social components, mastering psycho-physiological relaxation skills.

Training sessions consist of role-playing, business games and exercises, psychogymnastics, elements of psychodrama, group discussion, role-playing technique, method of situation analysis, self-regulation methods, body-oriented psychotherapy, relaxation, informing, discussion, individual, group reflection and art therapy elements.

The classes in groups are organized in such a way that each meeting, except of the first one, begins with reflection, which provides feedback and enables the trainer to learn about the status of the participants, their mood and the desire to continue their work in the training. One of the most important and exciting moments for the participants in the training is a group scoring in the end of the lesson: whether everyone achieved the goals, what difficulties occurred, what feelings were experienced.

The training is intended for a group of 12-16 people, the target audience is the freshmen students of economic higher education, aged 17-18 years. The training program includes 8 classes of 2 academic hours each. The training program consists of four blocks, each of which corresponds to the components of our socio-psychological and psychophysiological adaptation, which were mentioned above.

The first block of studies focuses on the formation of self-presentation skills, increasing group cohesion, developing confidence in situations of communication with an unfamiliar person; familiarization with strategies for solving problem situations, developing skills for successful behavior in conflict.

The second block of studies is devoted to the development of attentiveness, observation, familiarity with the methods of quick learning of a large amount of information, as well as exercises on the development of memory, consideration and application of the techniques and exercises that contribute to the formation of flexibility, originality and speed of the processes of thinking. This block also provides an introduction to the basics of time 
management. Its goal is to teach first-year students to plan their time so that they have time for studying, getting acquainted with the new city, and solving domestic problems.

The third block of studies is aimed at developing self-regulation skills and personal stress resistance, training meditative and relaxation psychotechnics to reduce adaptive stress, acquaintance with the basics of autogenous training.

The fourth block is the formation of the motives of goal achievement in adapting to professional activity, the skills of goal-setting and realization, understanding and constructing a model of the situation and positive images ("I am the past", "I am the present", "I am the future"); formation of healthy lifestyle skills and mobilization for success achievement.

The structure of the lesson includes the following parts: 1) the ritual of greetings; 2) warming-up (exercises for establishing contact, creating a friendly atmosphere in the group, activating joint work); 3) the reflection of the previous lesson; 4) agenda of the lesson (informing about the topic of today's classes, forms and methods of work depends on the tasks set in the class); 5) sharing (feedback by the group members); 6) the ritual of farewell.

\section{Conclusions and perspectives of further research}

An analysis of literature sources on the researched problem has shown that there is now a significant evolution of understanding the phenomenon of adaptation, which is marked by the following trends: there is an increasing division of concepts of adjustment and adaptation itself; the movement from passive adaptation to the construction of a system of productive interaction between personality and environment, from the ultimate goal - homeostatic balance, the absence of conflicts - to self-actualization and self-realization of the individual in a real social environment. Also, the process of adaptation is considered as behavior, due to the relationship of psycho-physiological, in fact, psychological and socio-psychological patterns. Over time, the concept of adaptation passed into the line of psychological science, where it developed under the influence of behaviorism, psychoanalysis, humanistic and cognitive psychology, labour psychology. In both traditional and modern studies of socio-psychological adaptation, it is accepted to distinguish between two main criteria of adaptability: external (adaptability, compliance with environmental requirements) and internal (general psychological well-being, comfort, subjective satisfaction with their position, social wellbeing).

We see further work in terms of socio-psychological adaptation first-year students in economic universities in the development of the properties of their personality and individuality, formation of creative strategies for adaptive behavior in the labor market, professional orientation and self-realization, readiness to choose a career, ability to identify and achieve the set goals. The following tasks of psychological support of freshmen arise: psychological study of students; assisting freshmen in their professional and personal selfdetermination; provision of conditions for personal and professional development; formation of optimal adaptive strategies in the labor market; psychological counseling for students and their parents, university lecturers.

\section{References}

Agadzhanyan, N.A., Smirnov, V.M. (2009). Normal physiology: a textbook for students of medical schools. Moscow: "Publishing house" Medical News Agency. [in Russian]. 
Alekseeva, T.V. (2004). Psychological factors and manifestations of the process of adaptation of students to higher education. Dissertation Abstract, Kiev, 26. [in Ukrainian].

Ananyev, B.G. (2002). Psychological structure of the personality and its formation in the process of individual development of a human. Psychology of personality. Reader. Samara: Ed. house "BAHRAH-M", 7-85. [in Russian].

Bayevskyi, R.M. (2004). Assessment of adaptive capabilities of the body and the problem of restorative medicine. Bulletin of Restorative Medicine, No. 2, 18-22. [in Ukrainian].

Berezin, F.B. (1988). Mental and psycho-physiological adaptation of a person. Lviv: Science. [in Ukrainian].

Clinciu, A.I. (2013). Adaptation and Stress for the First Year University Students. ProcediaSocial and Behavioral Sciences, Published by Elsevier B.V., Vol. 78, 718-722. [in English].

Dyson, R., Renk, K. (2006). Freshmen adaptation to university life: Depressive symptoms, stress, and coping. Journal of clinical psychology, Vol. 62, No. 10, 1231-1244. [in English].

Fetiskin, N. P., Kozlov, V. V., Manuylov, G. M. (2005). Socio-psychological diagnosis of personality and small groups development. Moscow: Publishing house of the Institute of Psychotherapy, 490. [in Russian].

Furman, A.V. (2000). Psychodiagnostics of personal adaptation: a scientific publication. Ternopil: "Economic thought", 197. [in Ukrainian].

Galus, O. M. (2012). To the problems of monitoring research of the peculiarities of the didactic adaptation of students of higher pedagogical educational institutions at the educational and qualification level "junior specialist". Pedagogical discourse, No. 12, 83-91. [in Ukrainian].

Glivinskyi, A. A., Mironchuk, N. M. (2015). Peculiarities of adaptation of first-year students to studies at a university. Professional training of specialists in the system of continuous education: a collection of scientific papers, 209-215. [in Ukrainian].

Heorhievskyi, A. B. (1989). Evolution of adaptation: historical and methodological research Lviv: Science. [in Ukrainian].

Kharchenko, S.V. (2010). Basic conceptual approaches in modern psychological science to study the peculiarities of adaptation of first-year students in the space of higher education as one of the stressful periods of their life. Science and Education, Southern Scientific Center of the Academy of Pedagogical Sciences of Ukraine, No. 3, 149-153. [in Ukrainian].

Kiseleva, M.V. (2007). Art therapy in practical psychology and social work. Saint Petersburg: Rech, 336. [in Russian].

Kokun, A.N. (2004). Optimization of the adaptive capabilities of students: methodological recommendations. Kiev: Millennium, 54. [in Ukrainian].

Kon, I. S. (1979). Psychology of adolescence: the problems of personality formation: Educational book. Moscow: Education, 175. [in Russian].

Meerson, F.Z., Pshennikova, M.G. (1988). Adaptation to stressful situations and physical stresses. Moscow: Medicine, 253. [in Russian].

Nalchadzhyan, A. A. (2010). Psychological adaptation: mechanisms and strategies. Moscow: Eksmo, 368. [in Russian].

Ostrova, V. D. (2015). Prospective identity as a factor in the socio-psychological adaptation of student youth. Dissertation Abstract. Kiev, 17. [in Ukrainian].

Park, C. L., Edmondson, D., Lee, J. (2012). Development of self-regulation abilities as predictors of psychological adjustment across the first year of college. Journal of Adult Development, Vol. 19, No. 1, 40-49. [in English]. 
Parker, James D.A., Summerfeldt, Laura J., Hogan, Marjorie J., Majeski, Sarah A. (2004). Emotional intelligence and academic success: examining the transition from high school to university. Personality and Individual Differences, No. 36, 163-172. [in English].

Rean, A. A., Kudashev, A.R., Baranov, A.A. (2006). Psychology of personality adaptation. Analysis. Theory. Practice. Saint Petersburg: Prime-Euroznak, 479 p. [in Russian].

Semichenko, V.A., Galus, A.M. (2003). Psychology of orientation: the teaching method. Khmelnitsky: KhGPI, 521. [in Ukrainian].

Vachkov, I.V. (2001). Fundamentals of group training technology. Psycho-technics: a study guide. Moscow: Publishing house "Axis-89", 224 p. [in Russian].

Westbrook, D., Kennerly, G., Kirk, J. (2014). Introduction to cognitive-behavioral therapy. Lviv: Science. [in Ukrainian]. 